\title{
MODELAGEM GRAVIMÉTRICA DO COMPLEXO ALCALINO DE ARAXÁ
}

\author{
Gilmar Rodrigues, Marta Mantovani, André Rugenski, Wladimir Shukowsky \\ Departamento de Geofísica, IAG/USP \\ gilmarrc@iag.usp.br; marta@iag.usp.br; andrerug@iag.usp.br; wladimir@iag.usp.br
}

\section{Resumo}

A identificação do processo de alojamento de intrusões alcalinas e a estimativa dos seus volumes contribui para uma visão da tectônica regional. Apresenta-se aqui o estudo gravimétrico do Complexo Alcalino de Araxá, na Província Ígnea do Alto Paranaíba, intrudido em quartzitos e xistos de idade proterozóica. O quartzito predomina próximo ao contato com a intrusão, formando um anel que se extende lateralmente entre 100 e 600 metros. O complexo alcalino apresenta estrutura circular (4,5 km de diâmetro) constituído por rochas ultramáficas metassomatizadas cortadas por carbonatitos e fosforitos. A modelagem 3D dos dados gravimétricos levantados fornece um volume de cerca de $30 \mathrm{~km}^{3}$ equivalente a uma massa de $19 \mathrm{x}$ $10^{9}$ toneladas.

\section{Introdução}

O processo de intrusão de corpos alcalinos pode ser expresso por uma variedade de manifestações tectônicas e epirogenéticas, tais como: domeamento devido à presença de pontos quentes (Crough, 1993), rifts continentais (Morgan \& Baker, 1983), bacias plataformais e soerguimento de platôs.

Historicamente, o Complexo Alcalino de Araxá e sua estruturação em domos, só vieram a ser caracterizados entre 1953 e 1954, pela Prospec S.A., para o DNPM, após os estudos sobre a apatita (Guimarães, 1947, Barbosa et al., 1970) e a descoberta do pirocloro (Ilchenko \& Guimarães, 1954; Barbosa et al., 1970). Estes trabalhos motivaram o primeiro levantamento geofísico sistemático da região a partir de 1972, confirmando assim, a presença de rocha alcalina (Seer,1998).

Estudos geológicos na área incluíram a realização de sondagem profunda. A observação dos testemunhos de sondagens mostra que o carbonatito ocorre principalmente como um sistema complexo de veios e diques, de alguns milímetros a vários metros de espessura, respectivamente penetrando as rochas glimeríticas. As injeções de carbonatitos ocorrem em fases diversas e a estrutura em brechas é uma feição proeminente neste corpo. Nota-se na intrusão uma intensa fase hidrotermal atuante devido à presença de glimeritos e da estrutura fraturada (Fig. 1).

Geologia da Área.

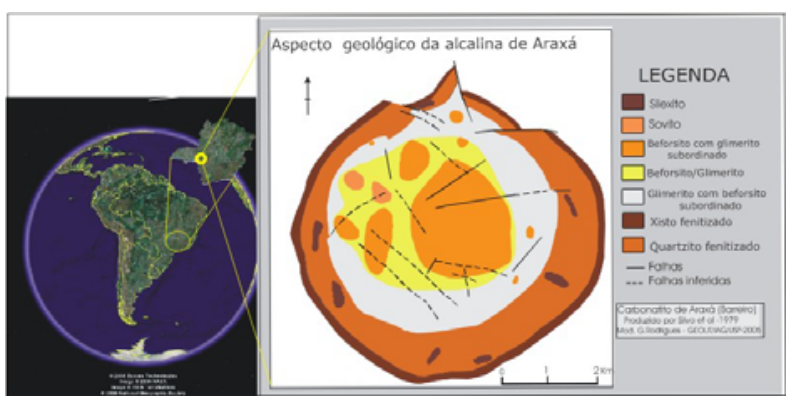

Figura 1. Superfície geológica do Complexo Alcalino Carbonatítico de Araxá (extraído de Grossi-Sad \& Torres,1976).

O carbonatito metassomático derivado de um provável piroxenito foi observado em testemunhos de sondagem extraídos da porção centro-oeste de Araxá; esse carbonatito preserva a textura da rocha ígnea original (Mariano et al., 1975). Sovitos típicos estão restritos à porção NW do complexo, ocorrendo também como diques estreitos nas rochas encaixantes (Silva et al, 1979). 
O flogopitito é a rocha mais abundante, constituindo a encaixante dos eventos magmáticometassomáticos cujos produtos são observados no Complexo Alcalino. Este é cortado por venulações milimétricas a centimétricas de material carbonatado. Foram observadas pelo menos duas gerações de carbonatito com diferentes texturas e granulações: uma constituída essencialmente por cristais de calcita, flogopita, ankerita e fenocristais de apatita; a segunda constituída de veios centimétricos de carbonato de composição dolomítica ferrosa e cristais de pirita euhédrica, que cortam o carbonatito anterior. Veios de apatita e magnetita apresentam-se intrudidos nos flogopititos e carbonatitos; veios de barita cortam todas as rochas anteriores e, ainda, existem veios de silexito com até seis metros de espessura e mergulho sub-horizontal (Torres \& Gaspar, 1995). Essa diversidade de minerais gera uma variação no comportamento geofísico da rocha, interferindo nas estimativas espaciais do corpo. Quando essas variações são ajustadas através de alguns poços de perfilagem, resultam num modelo mais confiável da jazida.

\section{Levantamento Gravimétrico}

O levantamento aerogeofísico do projeto Brasil-Alemanha (CPRM, 1972) forneceu as primeiras informações geofísicas do citado complexo que, atualmente, vem sendo palco de exaustiva explotação de carbonatito com extração de fosfato para a produção de fertilizantes. O levantamento gravimétrico terrestre de detalhe realizado para obter parâmetros físicos tais como forma, limites espaciais, massa e densidade, foi programado com base na resposta magnética da intrusão. Os dados gravimétricos foram adquiridos satisfazendo uma distribuição favorável à modelagem 3D da intrusão.

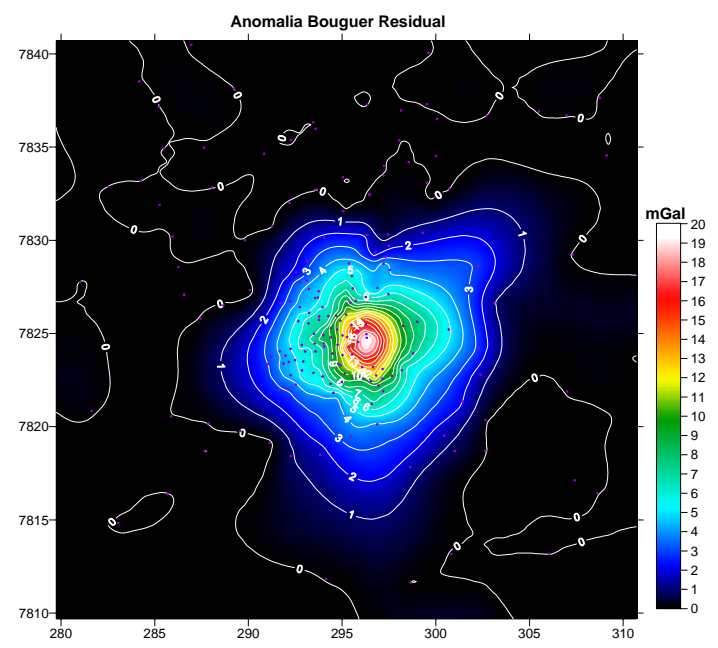

Figura 2. Componente residual da Anomalia Bouguer

Após eliminar da anomalia Bouguer obtida para a área levantada, o campo gravimétrico regional calculado pelo método da omissão (Mantovani et al., subm.), a amplitude máxima da anomalia gravimétrica residual resultou em 18 mGal (Fig. 2). Por ser positiva, indica que o corpo fonte da anomalia tem densidade superior à das rochas encaixantes refletindo a presença de uma rocha máfica-ultramáfica. $\mathrm{O}$ contraste de densidade utilizado, da ordem de $0,63 \mathrm{~g} / \mathrm{cm}^{3}$ para a profundidade modelada, resultou da diferença do valor médio de $2,67 \mathrm{~g} / \mathrm{cm}^{3}$ para a rocha encaixante (quartzito), e de $3,3 \mathrm{~g} / \mathrm{cm}^{3}$ para o complexo alcalino, que corresponde a um limite superior da densidade do piroxenito.

\section{Metodologia da Modelagem}

A modelagem 3D foi realizada através de ajustes em seções verticais (geometria 2,5 D) interligadas para obter uma componente tridimensional. Para o cálculo da anomalia produzida, o programa utiliza poliedros com forma irregular, tendo sido aqui assumido um único contraste de densidade. A integração do potencial gravitacional de cada poliedro fornece aquele do corpo modelado. Aplicando-se o gradiente obtémse o campo gravitacional sob forma de anomalia 
Bouguer; esta é comparada com a componente residual do campo medido (Fig. 3). O modelo apresentado utilizou o contraste de densidade acima citado $\left(0,63 \mathrm{~g} / \mathrm{cm}^{3}\right)$. Para valores inferiores de densidade do piroxenito o modelo resultará com uma raiz maior que $2,2 \mathrm{~km}$ e, em situações de maior densidade a raiz apresentará profundidades menores.

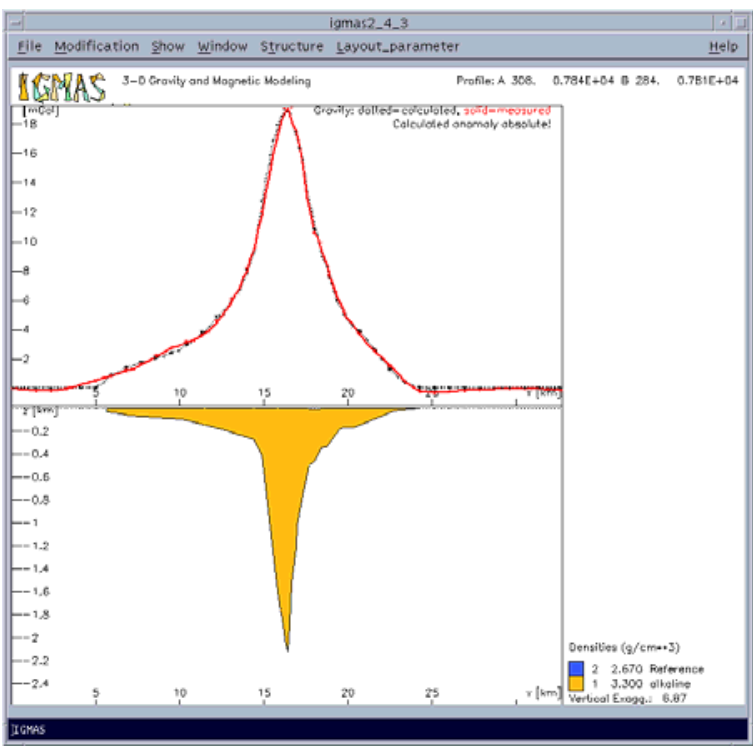

Figura 3. Exemplo de modelagem numa seção vertical.

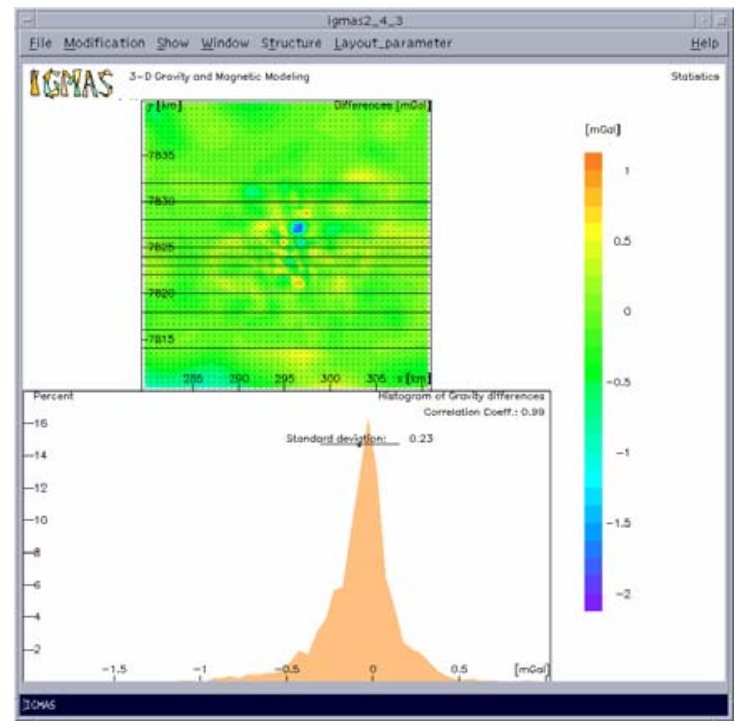

Figura 4. Análise estatística do modelo 3D de

Araxá.
A diferença entre o campo observado e aquele modelado é apresentada na Figura 4, juntamente com sua análise estatística, para a qual se obteve um coeficiente de correlação de 0,99..

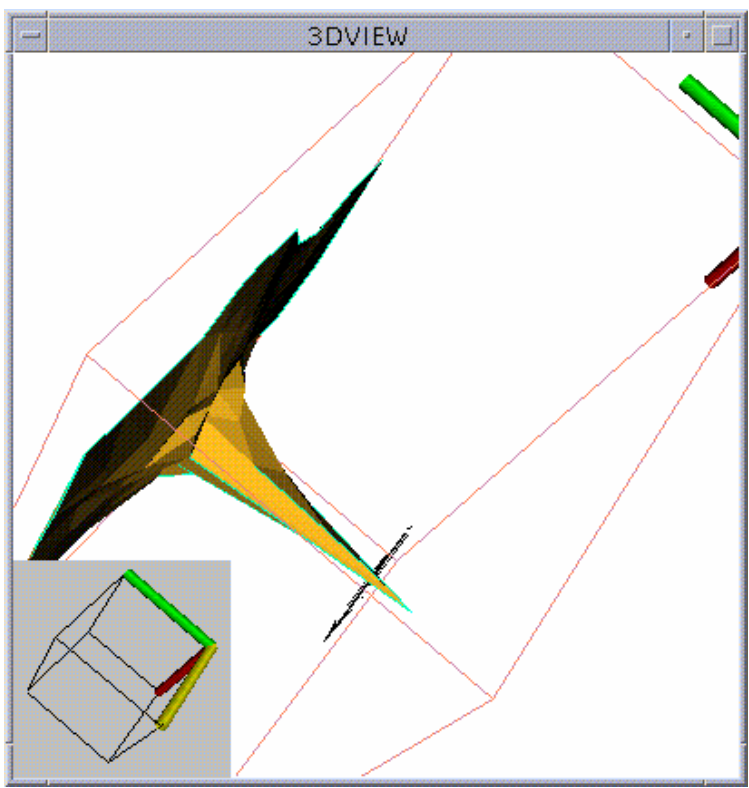

Figura 5. Imagem tridimensional da Alcalina de Araxá.

Uma comparação em perfil (2,5 D) entre o modelo obtido do sinal gravimétrico e do magnético (CPRM, 1972) é apresentada na Figura 6. Observa-se que a seção do corpo magnetizado e, portanto, seu volume é menor daquele do modelo gravimétrico, sugerindo a presença de minerais com menor susceptibilidade na borda do corpo relativamente à sua porção mais interna. 


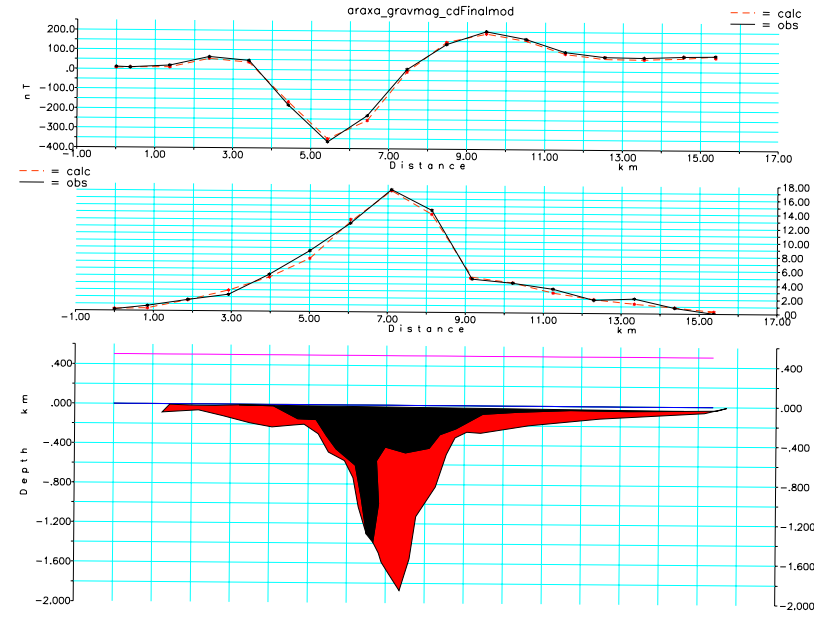

Figura 6. Modelo gravimétrico e magnético do complexo alcalino de Araxá utilizando uma geometria 2,5 D. A estrutura de cor vermelha representa o "corpo gravimétrico" e aquela de cor preta o "corpo magnético".

\section{Discussões e conclusões:}

Foi feito um levantamento gravimétrico cujos resultados permitiram traçar a anomalia Bouguer residual devida à presença do Complexo Alcalino de Araxá, para fins de modelagem desse complexo.

O Modelo apresentado sugere a presença de um corpo homogêneo, com formato cônico, semelhante a um "plug" com raiz, cuja litologia mais abundante pode ser o piroxenito ou o equivalente a teralitos e essexitos, ausentes em superfície.

Considerando a geometria modelada, os principais parâmetros físicos estimados foram: volume $29,680 \mathrm{~km}^{3}$ e massa 18.700 Mton, para a densidade média de $3,3 \mathrm{~g} / \mathrm{cm}^{3}$ do corpo e 2,673 $\mathrm{g} / \mathrm{cm}^{3}$ da encaixante (grupo Araxá); nestas condições a profundidade máxima da raiz é 2,2 $\mathrm{km}$. Os resultados apresentados fornecem uma visão do mecanismo de alojamento do complexo e seu volume total, considerando-se densidades médias do complexo e da encaixante fornecidas pelas observações geológicas.
No caso em estudo, a fácies litológica observada em superfície não se aprofunda mais de 200 metros, sendo que, em profundidade, as litologias como os piroxenito e suas associações são predominantes.

A comparação entre o modelo gravimétrico com geometria 2,5 D e aquele magnético indica uma ausência de magnetização na borda do corpo. Esta variação no valor da susceptibilidade pode ser indicativa de variações na mineralogia ou da superposição de várias componentes induzidas pelo campo magnético terrestre como conseqüência de diferenças na velocidade de resfriamento.

Os resultados aqui apresentados são preliminares e serão complementados para fins de mapeamento de estruturas e litologias de menor porte, como aquelas verificadas nos diques e "plugs".

A geometria 3D do Complexo Alcalino de Araxá resultante da modelagem efetuada é semelhante àquela de vários dos complexos alcalinos do SE brasileiro que apresentam respostas gravimétricas e magnéticas fortemente anômalas (ex.: Serra Negra, Tapira, Ipanema, entre outras; Rugenski et al., 2006).

\section{Agradecimentos}

Os autores agradecem o financiamento do levantamento gravimétrico ao CNPq, a disponibilidade dos dados aeromagnéticos à CPRM, e a autorização de acesso às áreas das minas à BUNGE e à CBPM.

\section{Referências:}

COSTA, M.L, 1993. IV Cong. Bras. Geoq., 195 197.

CPRM, 1972. Levantamento Aerogeofísico: Convênio Brasil-Alemanha (www.cprm.gov.br) 
ISSA FILHO, A.,.GROSSI SAD, J. H., (1984), Complexos Carbonatíticos do Brasil, CBMM, 44p. MANTOVANI, M.S.M., SHUKOWSKY, W., BRITO NEVES, B. B. de, RUGENSKI, A., 2006. Itapororoca Gravity Anomaly: A Geophyisical Contribution, Geophys. Prosp. (submetido)

TORRES, M.G.; GASPAR, J. C., 1995 Geoquímica do Manto de Intemperismo da Mina de Fosfato do complexo Alcalino-Carbonatitico do Barreiro Araxá -MG Resumo expandido: V Cong. Bras. Geoq. - UnB.

RUGENSKI, A., MANTOVANI, M. S. M., SHUKOWSKY, W., 2006. Investigação Gravimétrica do Complexo Alcalino de Ipanema, São Paulo, Brasil. Revista Geologia USP, Série Científica. (em publicação) 